\title{
Acute Respiratory Distress Syndrome With Alveolar Hemorrhage due to Strongyloidiasis Hyperinfection in an Older Patient
}

\author{
Eun Jin Kim \\ Department of Internal Medicine, Daegu Catholic University Medical Center, Daegu Catholic University School of Medicine, Daegu, Korea
}

Corresponding Author:

Eun Jin Kim, MD

https://orcid.org/0000-0001-9791-8077

Department of Internal Medicine,

Daegu Catholic University Medical

Center, 33 Duryugongwon-ro 17-gil,

Nam-gu, Daegu 42472, Korea

Tel: +82-53-650-4274

Fax: +82-53-650-4965

E-mail: ejkim77@cu.ac.kr

Received: October 19, 2018

Revised: November 29, 2018

Accepted: December 4, 2018
Strongyloides stercoralis is an intestinal nematode that occurs sporadically in temperate areas like Korea. People who are in the immunosuppressed state, over the age of 65 or under the corticosteroid therapy are at risk for developing Strongyloides hyperinfection syndrome. Acute respiratory distress syndrome (ARDS) with alveolar hemorrhage is a rare presentation of Strongyloides hyperinfection. A 78-year-old man had been irregularly injected corticosteroid on his knees, but did not have any immunosuppressive disease. He was initially diagnosed with ARDS and septic shock. Bronchoalveolar lavage (BAL) fluid was bloody and its cytology revealed helminthic larvae identified as S. stercoralis. Results of Cytomegalovirus polymerase chain reaction (PCR), Pneumocystis jirovecii PCR, and Aspergillus antigen testing of the BAL fluid were positive. The clinical progress quickly deteriorated with multiple organ failure, shock and arrhythmia, so he finally died. This is a rare case of ARDS in an older patient without any known immunosuppressive conditions, with alveolar hemorrhage and S. stercoralis being found via BAL. (Ann Geriatr Med Res 2018;22:200-203)

Key Words: Strongyloides stercoralis, Acute respiratory distress syndrome, Alveolar hemorrhage

\section{INTRODUCTION}

Strongyloides stercoralis is an intestinal nematode that causes an endemic disease in tropical and subtropical rural areas. ${ }^{1)}$ In Korea, which is in a temperate zone, several cases of Strongyloides hyperinfection have been reported, but these have been mostly associated with gastrointestinal involvement. ${ }^{2-4)}$ Two cases of pulmonary strongyloidiasis with acute respiratory failure and alveolar hemorrhage $e^{5,6)}$ have been reported, but these cases involved an immunosuppressed state owing to lung cancer and chemotherapy. I report a case of acute respiratory distress syndrome (ARDS) in an older patient without known immunosuppressive conditions, with alveolar hemorrhage and S. stercoralis being found via bronchoalveolar lavage (BAL).

\section{CASE REPORT}

A 78-year-old man visited the Daegu Catholic University Medical Center owing to aggravated dyspnea. He had diarrhea 10 days before admission, and dyspnea started 3 days before admission. He was previously diagnosed with hypertension and degenerative arthritis and intermittently received intra-articular injections of corticosteroids into his knee joints. He was a farmer and had never traveled overseas.
His arterial blood pressure was 110/60 $\mathrm{mmHg}$, pulse rate was 103 beats $/ \mathrm{min}$, body temperature was $38.9^{\circ} \mathrm{C}$, and respiratory rate was $28 / \mathrm{min}$. Crackling was heard in both lower lung fields. A complete blood count showed a leukocyte count of 8,300/ $\mu \mathrm{L}$ (90.4\% neutrophils, 6.1\% lymphocytes, and $0.7 \%$ eosinophils), a hemoglobin level of $9 \mathrm{~g} / \mathrm{dL}$, and a platelet count of $200 \times 10^{3} / \mu \mathrm{L}$. Laboratory tests showed the following blood levels: aspartate aminotransferase, $66 \mathrm{U} / \mathrm{L}$; alanine transaminase, $137 \mathrm{U} / \mathrm{L}$; gamma-glutamyltransferase, $90 \mathrm{U} / \mathrm{L}$; blood urea nitrogen, $23.6 \mathrm{mg} / \mathrm{dL}$; creatinine, $0.6 \mathrm{mg} / \mathrm{dL} ; \mathrm{Na}, 131 \mathrm{mEq} / \mathrm{L} ; \mathrm{K}, 3.7$ $\mathrm{mEq} / \mathrm{L}$; total protein, $4.8 \mathrm{~g} / \mathrm{dL}$; and albumin, $2.6 \mathrm{~g} / \mathrm{dL}$. The levels of pro-B-type natriuretic peptide and C-reactive protein at $1,414 \mathrm{pg} / \mathrm{mL}$ (normal range, $9-113.2 \mathrm{pg} / \mathrm{mL}$ ) and $368 \mathrm{mg} / \mathrm{L}$ (normal range, $<5 \mathrm{mg} / \mathrm{L}$ ), were increased. The result of anti-HIV antibody screening was negative. The result of stool occult blood testing was positive, but no parasites or eggs were found in the stool. Arterial blood gas analysis showed $\mathrm{pH} 7.500, \mathrm{pCO}_{2} 22.5 \mathrm{mmHg}, \mathrm{pO}_{2} 84.4$ $\mathrm{mmHg}, \mathrm{HCO}_{3} 17.2 \mathrm{mmol} / \mathrm{L}$, and peripheral oxygen saturation $\left(\mathrm{SpO}_{2}\right)$ 97.3\% under a fraction of inspired oxygen $\left(\mathrm{FiO}_{2}\right)$ of 0.6 .

No microorganisms were detected in blood and sputum cultures. Results of a sputum acid fast bacillus (AFB) smear and Mycobacterium tuberculosis polymerase chain reaction (PCR) were negative. 
Chest radiography revealed bilateral and diffuse nodular infiltration and multiple patchy opacities in both whole lung fields and a cavity in the left hilar area (Fig. 1A). Chest computed tomography (CT) showed multiple consolidation, ground-glass opacity, and centrilobular nodules in both lungs and several thin-walled cavities in the right upper lobe and left lower lobe, with septa inside the cavities (Fig. 1B). Abdominal CT showed diffuse bowel wall edema along the ascending and transverse colon.

As a result of the above findings, ARDS, pneumonia, and sepsis were diagnosed, and treatment with piperacillin/tazobactam and ciprofloxacin was initiated along with oxygen therapy. At 14 hours after admission, as the patient's $\mathrm{SpO}_{2}$ decreased to $83 \%$ and his respiratory rate increased to 32 breaths/min, intubation and ventilator treatment was initiated. Hemoptysis was confirmed from the time of tracheal intubation and persisted thereafter. On the first day of admission, the patient's blood pressure had decreased, and he was treated with fluid and inotro- pic support based on the diagnosis of septic shock. On the third day of admission, bronchoscopy was performed and showed large blood clots in both bronchi and diffuse alveolar hemorrhage in the lower parts of the bronchi when the blood clot was removed (Fig. 2A). BAL was performed from the right upper lobe bronchus, where cavities were located. The lavage fluid was bloody (Fig. 2B), a bacterial culture was negative, and the results of an additional AFB smear and $M$. tuberculosis PCR were negative. The results of Cytomegalovirus (CMV) PCR, Pneumocystis jirovecii PCR, and Aspergillus antigen testing of the BAL fluid were positive.

On the fourth day of admission, the patient's blood pressure decreased with the onset of ventricular tachycardia on electrocardiography. His $\mathrm{FiO}_{2}$ increased from 0.65 to 1.0 owing to increasing oxygen demand. On the eighth day of hospitalization, a cytologic examination of the BAL fluid confirmed the filariform larvae of $S$. stercoralis (Fig. 3), but the patient died on the day of the diagnosis, before
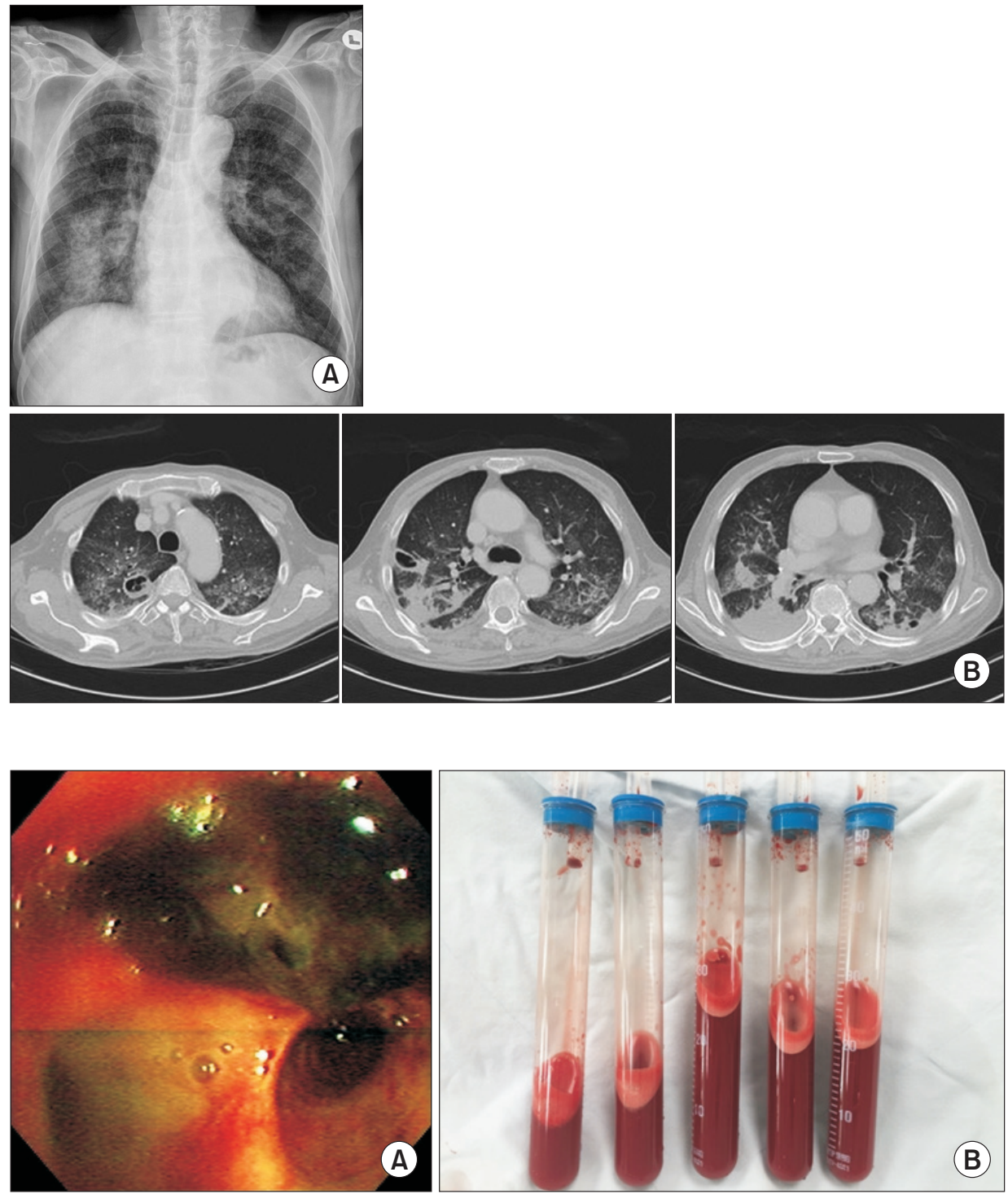

Fig. 1. (A) A chest radiograph shows bilateral and diffuse nodular infiltration and multiple patchy opacities in both whole lung fields, and a cavity in left hilar area. (B) Chest computed tomography scans reveal several thin-walled cavities in the right upper lobe and left lower lobe, and multiple consolidations, ground glass opacities and centrilobular nodules in both lungs.

Fig. 2. (A) Bronchoscopy shows that the large blood clot plugged in the right upper lobe bronchus with hemorrhagic mucosa. (B) Bronchoalveolar lavage fluid shows bloody in appearance. 


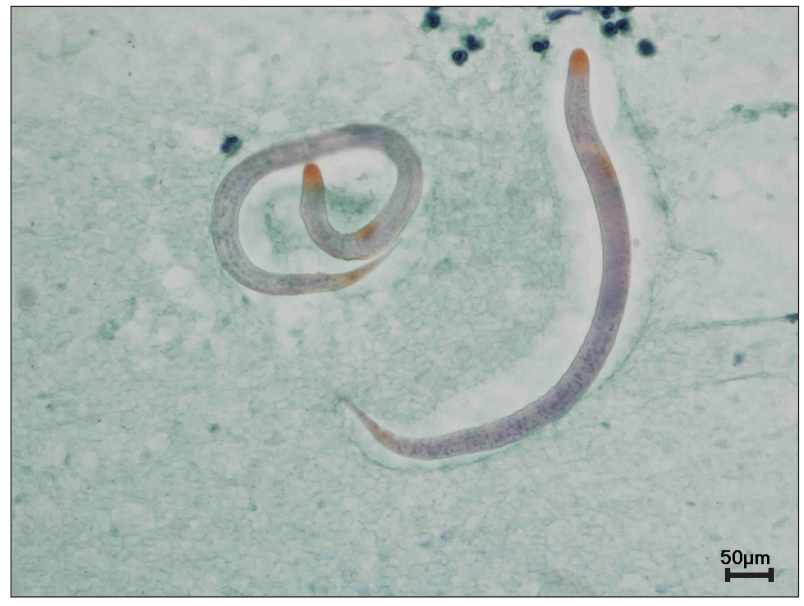

Fig. 3. Microscopic view of the bronchoalveolar lavage fluid shows filariform larvae of Strongyloides stercoralis (Gomori methenamine silver stain, $\times 400$ ).

administration of the therapeutic agent.

\section{DISCUSSION}

Presented here is a case of Strongyloides hyperinfection presenting as ARDS and alveolar hemorrhage in an older patient in Korea with no immunosuppressive conditions.

Strongyloides hyperinfection is the term often used for the phenomenon in which the number of $S$. stercoralis organisms increases dramatically and worms are found especially in extraintestinal regions. ${ }^{7}$

S. stercoralis has the ability to reinfect within the human body, which is known as autoinfection, and it can live in the human body for extended periods of time, greatly increasing the parasite burden. Therefore, autoinfection can lead to hyperinfection, resulting in the development of complications involving the gastrointestinal tract, lungs, and peritoneum. ${ }^{7,8)}$

Hyperinfection risk factors include decreased cellular immunity, age $\geq 65$ years, chronic lung diseases, intestinal blind loops, achlorhydria, and the use of corticosteroids, antacids, or $\mathrm{H} 2$ blockers. ${ }^{3,9)}$ The use of corticosteroids was the main triggering factor that induced hyperinfection, but the cumulative dose or duration of the corticosteroid treatment causing Strongyloides hyperinfection was not known. ${ }^{10)}$ The patient in the present report had no history of systemic corticosteroid use, but he did undergo intraarticular corticosteroid injections. Intra-articular corticosteroids also have systemic side effects and may have been a risk factor for strongyloidiasis. In this case, I think that it was important to show that intra-articular corticosteroid injection could cause Strongyloides hyperinfection. Aging can be a risk factor as aging affects the function or number of T-cells. ${ }^{9)}$

Peripheral eosinophilia may be absent in hyperinfection owing to the use of corticosteroids or the suppression of eosinophils due to bacterial infection. ${ }^{9,11)}$ Nabeya et al. ${ }^{8)}$ re- ported that there was no eosinophilic manifestation among 16 severe strongyloidiasis cases.

In hyperinfection, the larvae damage the intestinal mucosa and carry the enteric bacteria on their outer surfaces, resulting in bacterial and fungal infections often accompanied by leakage of gut flora. ${ }^{77}$ Massive secondary infections are a major cause of death. ${ }^{7)}$ Strongyloides hyperinfection presented clinically with gram-negative sepsis in some reports. ${ }^{12)} \mathrm{CMV}$ has been reported as a coinfection of $S$. stercoralis hyperinfection in cases of transplantation and HIV-1 infection. ${ }^{13,14)}$ In the present case, there was a coinfection with CMV, P. jirovecii, and Aspergillus spp., proven in the BAL fluid findings.

The patient presented here might have been exposed to $S$. stercoralis while walking barefoot in rice paddies, and the risk factors of older age and intermittent intra-articular administration of steroids may have led to Strongyloides hyperinfection. Given the presence of $P$. jirovecii and CMV as shown via PCR and Aspergillus antigen in BAL fluid, it is presumed that the vigorous movement of the larvae caused extensive bacterial, viral, and fungal infections, leading to the death of the patient.

In hyperinfection, respiratory specimens aid in the detection of parasites and larvae. ${ }^{9)}$ The prognosis varies depending on the severity of the strongyloidiasis, but the mortality rate exceeds $70 \%-80 \%$ despite appropriate treatment. ${ }^{9)}$

Strongyloidiasis with acute respiratory failure and pulmonary hemorrhage is rare and almost is accompanied by an immunodeficiency disease. ${ }^{5,6,8,12)}$ In the present case, there was no definite underlying disease, but there was a history of intra-articular corticosteroid injection and old age. This is significant because Strongyloides hyperinfection may be associated with coinfection with CMV, P. jirovecii, and Aspergillus spp.

In Korea, the number of older patients with immunodeficiency due to the deterioration of biologic functions is increasing, and the chances of serious infections due to various parasites are increasing even in the absence of immunosuppressive disease. ${ }^{15)}$ Strongyloidiasis is difficult to diagnose because of the low parasite burden in Korea and the irregular larval output. ${ }^{12)}$ I report a case of S. stercoralis hyperinfection presenting as ARDS and alveolar hemorrhage in an older patient with no known immunosuppressive disease. In rare cases of ARDS accompanied by gastrointestinal symptoms in older patients, suspicion of parasitic infection and appropriate testing to confirm this suspicion may help to speed up the diagnosis and treatment of patients.

\section{CONFLICTS OF INTEREST DISCLOSURES}

The researcher claims no conflicts of interest. 


\section{REFERENCES}

1. Schär F, Trostdorf U, Giardina F, Khieu V, Muth S, Marti H, et al. Strongyloides stercoralis: global distribution and risk factors. PLoS Negl Trop Dis 2013;7:e2288.

2. Choi KS, Whang YN, Kim YJ, Yang YM, Yoon K, Kim JJ, et al. A case of hyperinfection syndrome with Strongyloides stercoralis. Korean J Parasitol 1985;23:236-40.

3. Kim YK, Kim H, Park YC, Lee MH, Chung ES, Lee SJ, et al. A case of hyperinfection with strongyloides stercoralis in an immunosuppressed patient. Korean J Intern Med 1989;4:165-70.

4. Choi SI, Hong SW, Lee KG. Hyperinfection syndrome with Strongyloides stercoralis: report of a case. Korean J Pathol 1989;23:35964.

5. Kim HS, Kim YE, Yun EY, Ju JH, Ma JE, Lee GD, et al. A case of fatal hyperinfective Strongyloidiasis with acute respiratory failure and intestinal perforation in lung cancer Patient. Tuberc Respir Dis 2010;68:29-33.

6. Kim YJ, Ahn MJ, Park KC, Lee HY, Kim KH, Byeon KM, et al. Pulmonary Strongyloidiasis with alveolar hemorrhage in a patient receiving chemotherapy. Korean J Med 2009;76:502-5.

7. Siddiqui AA, Berk SL. Diagnosis of Strongyloides stercoralis infection. Clin Infect Dis 2001;33:1040-7.

8. Nabeya D, Haranaga S, Parrott GL, Kinjo T, Nahar S, Tanaka T, et al. Pulmonary strongyloidiasis: assessment between manifestation and radiological findings in 16 severe strongyloidiasis cases. BMC Infect Dis 2017;17:320.

9. Woodring JH, Halfhill H 2nd, Reed JC. Pulmonary strongyloidiasis: clinical and imaging features. AJR Am J Roentgenol 1994;162:537-42.

10. Buonfrate D, Requena-Mendez A, Angheben A, Muñoz J, Gobbi F, Van Den Ende J, et al. Severe strongyloidiasis: a systematic review of case reports. BMC Infect Dis 2013;13:78.

11. Lam CS, Tong MK, Chan KM, Siu YP. Disseminated strongyloidiasis: a retrospective study of clinical course and outcome. Eur J Clin Microbiol Infect Dis 2006;25:14-8.

12. Tsai MJ, Wu TS, Tsai KB, Chen HC, Hwang JJ, Huang MS. Acute respiratory distress syndrome complicating Strongyloides stercoralis hyperinfection. Int J Gerontol 2011;5:53-5.

13. Weiser JA, Scully BE, Bulman WA, Husain S, Grossman ME. Periumbilical parasitic thumbprint purpura: strongyloides hyperinfection syndrome acquired from a cadaveric renal transplant. Transpl Infect Dis 2011;13:58-62.

14. Mizuno S, Iida T, Zendejas I, Martin TD, Schain DC, Turner B, et al. Strongyloides hyperinfection syndrome following simultaneous heart and kidney transplantation. Transpl Int 2009;22:251-3.

15. Lee DC, Chang MH, Kyung SE. A case of angiographically angiitis with acquired toxoplasmosis in elderly patient. J Korean Geriatr Soc 2006;10:47-51. 